\title{
Modification of Concrete Railway Sleeper Mix Design, Using a Hybrid Application of Steel Fibers
}

\author{
Jun Wang ${ }^{1}$, Mohammad Siahkouhi ${ }^{2}$, Farshad Astaraki ${ }^{3}$, \\ Sashka Uuganbayar², Guoqing Jing ${ }^{2}$, Majid Movahedi Rad ${ }^{3 *}$
}

${ }^{1}$ Shijiazhuang Tiedao University, 1 Longshan Road, Jicun Town, Yuanshi County, Shijiazhuang, 051130 Hebei, P.R.China; wangjun2011@stdu.edu.cn

${ }^{2}$ School of Civil Engineering, Beijing Jiaotong University, No. 3 Shangyuancun Haidian District, 100044 Beijing, China; m.siahkouhi@bjtu.edu.cn, 19119903@bjtu.edu.cn, gqjing@bjtu.edu.cn

${ }^{3}$ Department of Structural and Geotechnical Engineering, Széchenyi István University, Egyetem tér 1, 9026 Györ, Hungary astaraki.farshad@hallgato.sze.hu,majidmr@sze.hu

Abstract: Concrete railway sleepers have been used for years without an update in production and design, to be compatible with demands for increasing train axle loads and speed. In the current research, concrete railway admixture is modified with consuming $(0.5 \%$ straight-1.5\% hooked), (1.5\% straight-0.5\% hooked) and (1\% straight-1\% hooked) steel fibers combinations. Three main mechanical experiments as compressive, flexural and splitting tensile strengths and fresh mortar "flowability" were performed. Results showed that the hybrid of $1 \%$ straight and $1 \%$ hooked steel fibers shows the optimal performance among other hybrid combinations. This hybrid admixture efficiently improves the compressive, flexural and splitting tensile strengths of the concrete railway sleeper mix design.

Keywords: Concrete railway sleeper; Steel fibers; Optimal hybrid reinforced concrete

\section{Introduction}

Railway sleeper are one the critical components of railway tracks, which have a role to distribute and decrease train loads from the rail foot to the underlying ballast bed and consequently to subgrade [1-3]. The traditional sleepers are manufactured using timber, concrete and steel [4]. Wooden sleepers are contained in the majority part of railway tracks, but concerning their environmental disadvantages, were gradually replaced by the other types of sleepers [5]. In order to replace wooden sleepers, steel 
sleepers, as an alternative, were used [6]. Considering the performance of steel sleepers, they face problems in high speed of train and corrosion issues [7].

Concrete sleepers are extensively used in railway engineering [8]. Their performance in railway tracks leads to less maintenance cost, track stability and longer life cycles [9-, 10, 11, 12]. Pre-stressed concrete has different kinds that mono-block concrete sleeper is one of the most popular kinds implemented in railway tracks [13]. Recently, by increasing axle load, speed and traffic, finding a better quality of concrete sleepers is an approach. The common behaviors of sleepers under overloading or fatigue are tensile fracture, longitudinal and cross cracks under rail seat of railway tracks [20] [21]. Occasionally, it has been seen that the tensile strength of sleepers is not enough and leads to some physical damage. An effective solution is use of fiber reinforced concrete. Consuming short, discrete or long fibers lead to a new construction material challenges [14]. Fiber-reinforced concrete (FRC) is produced in different types mixed during fresh concrete production [15], and leads to an increase in mechanical performance of concrete [16]. Almost four popular kinds of fibers fabricated from steel, plastic, glass, and natural materials are consuming in a variety of shapes, sizes, and thicknesses. Three kinds of steel fibers in shapes of straight, hooked and crimped are commonly preferred to use [17]. It is concluded that using hybrid shape of steel fibers has the best influence on concrete performance [18].

Recently, by proving the performance of steel fibers in concrete admixtures, some researchers have tried to assess its behavior combined with concrete sleeper admixtures. Sadeghi et al. [19] followed two approaches, firstly, the effects of straight steel fibers on the mechanical behavior of pre-stressed concrete sleepers with the different percentages in contents of $(0,0.3,0.5,0.7$ and $1 \%$ by volume) and, secondly, decreased the number of pre-stressed rebars. The results indicate that consuming steel fibers in concrete sleeper admixtures leads to an improvement in the sleeper bending strength, energy absorption capacity, and cracking resistance increase. Zhu et al. [20] investigated the effects of straight steel fibers on production cost and cracks opening in a concrete beam with polymer rebars. The results showed that all parameters of crack width, ductility and cost decreased due to presence of steel fibers. Shin et al. [21] assessed the effects of straight steel fibers mixed with different kinds of fine aggregates in pre-stressed concrete railway sleeper admixtures. The results showed that the fraction of $0.75 \%$ of steel fibers mixed with slag concrete leads to enhance its static and impact flexural capacity. Parvez and Foster [22] inspected the performance of straight steel fibers in carrying capacity and fatigue of railway sleepers. Pre-stressed concrete sleepers were researched with fiber contents of $0,0.25 \%$ and $0.5 \%$ by volume, under cyclic and static loading. The sleepers with $0.5 \%$ fibers have higher static capacity and extended fatigue life, lower deflections and finer crack widths compared to those sleepers without fibers. Moreover, Hwang et al. [23] tried to design pre-stressed sleepers with $0.75 \%$ steel fibers by volume and features of $30 \mathrm{~mm}$ length and aspect ratio of 55 [24]. Results showed that toughness and durability of sleepers were improved. 
None of the aforementioned papers have assessed hybrid behavior of steel fibers in railway concrete sleeper mix design. In order to decrease fiber content and increase mechanical performance of concrete, hybrid use of steel fibers with low aspect ratio is proposed that consequently, reduce the disadvantages of the presence of steel fiber in concrete admixtures. Therefore, in the current research, respect to different admixture and low aspect ratio of steel fibers, performance of single and hybrid steel fibers are investigated, to improve concrete railway sleeper mix design.

\section{Experimental Program}

\subsection{Concrete Sleeper Test}

The sleeper under test is a commercially available mono-block type used for high speed railways. The pre-stressed concrete sleeper consists of almost $320 \mathrm{~mm} \times 260$ $\mathrm{mm} \times 2600 \mathrm{~mm}$ dimensions with 10 numbers of $\varnothing 7 \mathrm{~mm}$ strands. The lowest width and height of the sleeper structure are by $280 \mathrm{~mm}$ and $185 \mathrm{~mm}$, respectively. European standard EN 13230-2 [25] provides guidelines for calculating reference test loads for different concrete sleeper types. As shown in Figure 1, sleeper is tested in middle negative bending moment test with flexural strength of $70 \mathrm{kN}$, (the load that the first crack is identified by operator using portable microscopes). Figure 2 shows load against deflection of sleeper under flexural load. Load is applied until $140 \mathrm{kN}$ to capture bending behavior of sleeper. Until $20 \mathrm{kN}$, sleeper shows more flexibility and less stiffness, however, it has a sharp increase in sleeper stiffness after $20 \mathrm{kN}$ flexural load. The first crack has been seen in almost $70 \mathrm{kN}$, when the sleeper stiffness has been reduced again due to the crack initiation.

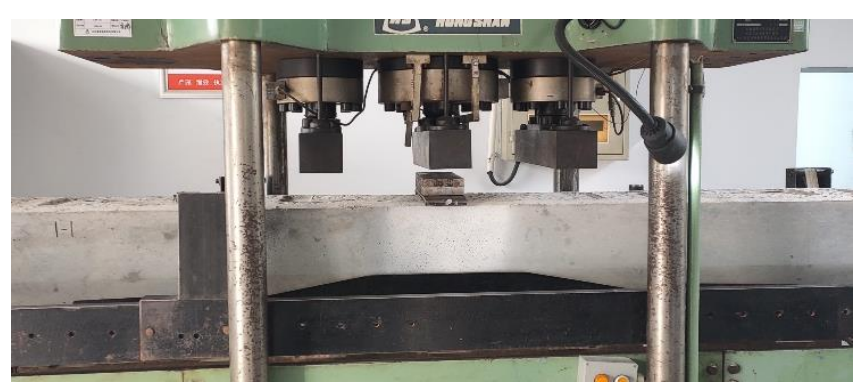

Figure 1

The middle negative bending moment test 


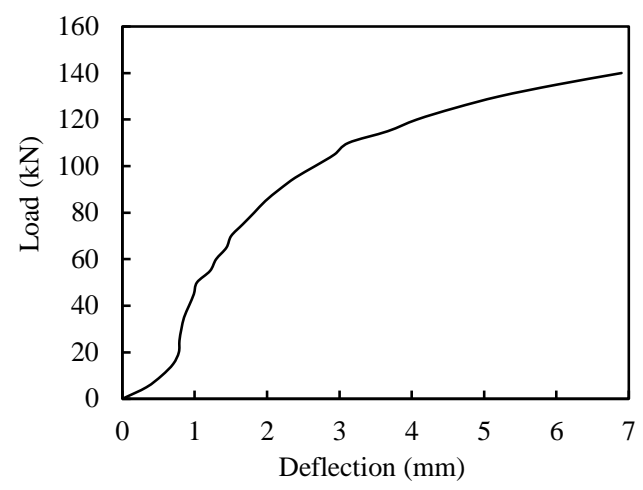

Figure 2

The flexural strength of concrete sleeper

\subsection{Steel Fiber Reinforced Concrete}

\subsubsection{Materials and Mix Proportion}

Ordinary Portland Cement (II) and silica fume was consumed in this research. A polycarboxylate superplasticizer including air entraining agent, $40 \%$ solid and $60 \%$ water with specific gravity of 1.09 and solid contents of $32 \%$ was used in all the concrete mixtures. Furthermore, steel fibers with properties according to the Table 2 have been used. 4 mixtures are presented in Table 1, Ref. mixture is without any steel fiber and is concrete sleeper mix design. The workability and mechanical properties of the concrete mixtures were considered to select the optimal admixture with hybrid use of steel fibers. To combine powder materials with concrete admixture, they are mixed before the water and superplastisizer addition, in this way particle agglomeration can be avoided. Firstly, the fine aggregates are mixed in the mixer contains quartz sand. Afterwards, the powder materials are added to mixer's contents and mixed for around 4 minutes. Then almost half of the $2 \%$ (by cement weight) high-range superplastisizer is diluted in the admixture water and is gradually added within 2 minutes. The remaining superplastisizer are gradually added during a next 4 minutes of mixing. Steel fibers are added in three parts, in first, middle and almost at the end of mixing time. The fresh concrete is placed in two kinds of molds as $100 * 100 * 400 \mathrm{~mm}$ prismatic and $100 \mathrm{~mm}$ cubical. Vibration table is used for 2 minutes. The specimens without movement are covered with plastic sheets and are kept at $240{ }^{\circ} \mathrm{C}$ for a day before demolding. After demolding, the samples are cured in an autoclave system with heat and vapor. By using this system, concrete sleeper cure system is simulated as Figure 3. Firstly, specimens are cured at $20{ }^{\circ} \mathrm{C}$ for 73 hours of cure time, then the heat is smoothly raised to $90{ }^{\circ} \mathrm{C}$. This much heat is stable for 50 hours, afterwards, it is slowly reduced to 
$20{ }^{\circ} \mathrm{C}$ again (Fig. 2). It should be mentioned that for validity of test results for each mix, 3 specimens are constructed and tested.

Table 1

Concrete admixtures

\begin{tabular}{|l|l|l|l|l|l|l|l|l|}
\hline No. & Cement & Quartz & Silica & & & \multicolumn{2}{|l|}{ Volume content (\%) } & \\
\cline { 7 - 9 } & sand & fume & & Water & Admixture & Straight fiber & $\begin{array}{l}\text { Hooked } \\
\text { fiber }\end{array}$ & Notation \\
\hline 1 & 706 & 1255 & 160 & 124 & 68 & - & - & Ref. \\
\hline 2 & 706 & 1255 & 160 & 124 & 68 & 0.5 & 1.5 & S05H15 \\
\hline 3 & 706 & 1255 & 160 & 124 & 68 & 1 & 1 & S10H10 \\
\hline 4 & 706 & 1255 & 160 & 124 & 68 & 1.5 & 0.5 & S15H05 \\
\hline
\end{tabular}

$90{ }^{\circ} \mathrm{C}$

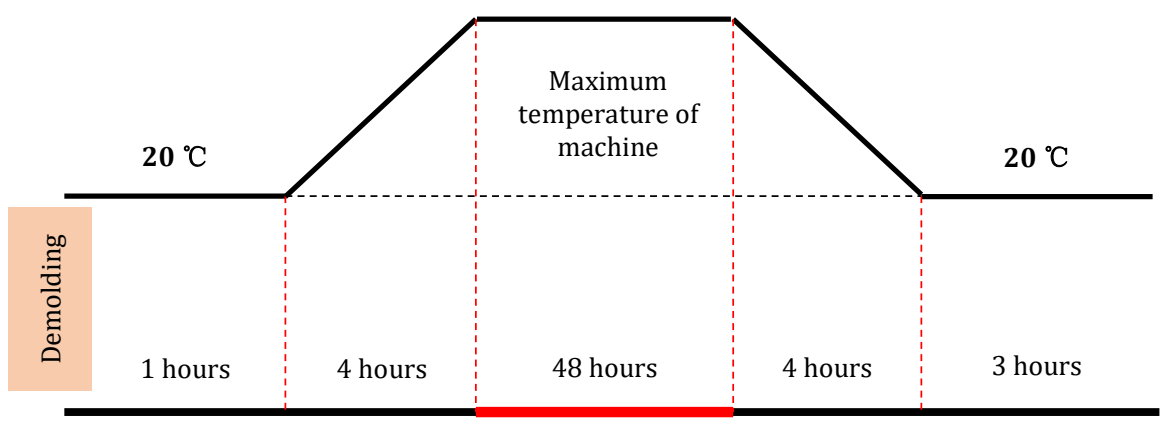

Figure 3

Steam curing process of concrete specimens in curing machine

Table 2

Steel fibers properties

\begin{tabular}{|c|c|c|c|c|c|c|c|}
\hline \multirow{2}{*}{$\begin{array}{c}\text { Type } \\
\text { of fiber }\end{array}$} & Diameter & Length & $\begin{array}{c}\text { Aspect } \\
\text { ratio }\end{array}$ & Density & $\begin{array}{c}\text { Tensile } \\
\text { strength }\end{array}$ & $\begin{array}{c}\text { Elastic } \\
\text { modulus }\end{array}$ & \multirow{2}{*}{ Picture } \\
\cline { 2 - 6 } & \multicolumn{2}{|c|}{$(\mathrm{mm})$} & $\left(\mathrm{l}_{\mathrm{f}} / \mathrm{d}_{\mathrm{f}}\right)$ & $\left(\mathrm{g} / \mathrm{cm}^{3}\right)$ & $(\mathrm{MPa})$ & $(\mathrm{GPa})$ & \\
\hline $\begin{array}{c}\text { Straight } \\
\text { fiber }\end{array}$ & 0.2 & 13 & 65 & 7.8 & 2850 & 200 & \\
\hline \multirow{2}{*}{$\begin{array}{c}\text { Hooked } \\
\text { fiber }\end{array}$} & 0.3 & 22 & 73 & 7.8 & 2850 & 200 & \\
\hline
\end{tabular}




\subsubsection{Compressive Strength Test}

The compressive strength results of different admixtures are shown in Figure 5. The results indicate that the presence of steel fiber increases compressive strength. Hybrid fiber content (S10H10) has more compressive strength as $171 \mathrm{Mpa}$ that shows better performance. Flowability of concrete mixtures is measured using slump test. S10H10 hybrid concrete has $108 \mathrm{~mm}$ flowability. It should be noted that in case of concrete sleeper production, the low value of flowability cannot make a significant problem, because in production procedure of concrete sleepers a special vibration system has been used that can overcome this much of low value of flowability. The references compressive strength is about $93 \mathrm{Mpa}$, which increased by adding hybrid fibers. S05H15 has a compressive strength value by $40 \%$ greater than Ref., these percentages for S10H10 and S15H05 are almost 45\% and 44\% higher, respectively. Therefore, the comparison of results shows that S10H10 admixture has the maximum value of compressive strength but with minimum flowability as $108 \mathrm{~mm}$.

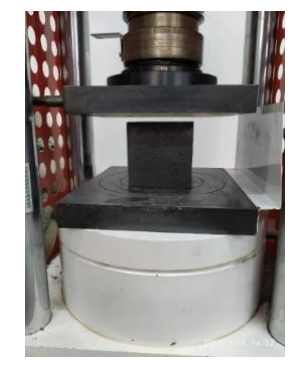

Figure 4

An overview of compressive strength test machine

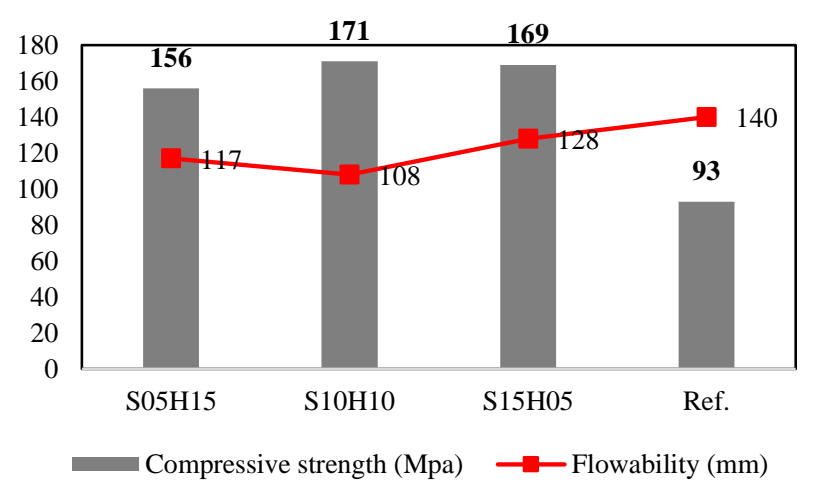

Figure 5

Compressive strength and flowability of concrete specimens 


\subsubsection{Flexural Strength Test}

Figure 6 shows flexural test instrument machine. The diagram of flexural strength for concrete admixtures is shown in Figure 7. The results indicate that addition of steel fiber results in a significant increase in the flexural strength value. The flexural strength of $\mathrm{S} 05 \mathrm{H} 15, \mathrm{~S} 10 \mathrm{H} 10$ and $\mathrm{S} 15 \mathrm{H} 05$ increase by 52\%, 55\% and 50\%, respectively, compared to Ref. It should be paid attention that the summation of total hybrid fiber percentage usage in every admixture is $2 \%$. For instance, $0.5 \%$ straight plus $1.5 \%$ hooked fibers equal to $2 \%$. Therefore, three kinds of hybrid admixtures do not show a significant difference but among those $\mathrm{S} 10 \mathrm{H} 10$ has better performance. It should be noted that performance of $2 \%$ hybrid fiber is $55 \%$ more than Ref. Concrete sleepers according to their loading pattern with trains, may face high bending moments, therefore, flexural strength is critical in their performance.

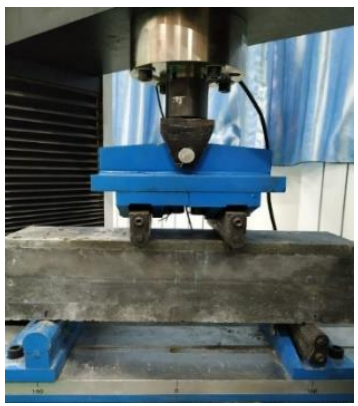

Figure 6

An overview of flexural test layout

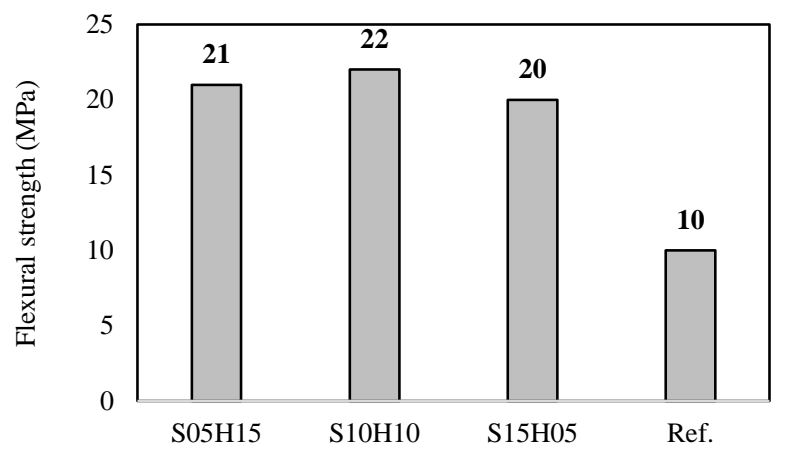

Figure 7

Flexural strength test results of concrete specimens 


\subsubsection{Splitting Tensile Strength}

The splitting tensile strength of the different admixtures were prepared in this study that are shown in Figure 10. Concrete has weakness in tension. Thus, splitting tensile strength test is necessary to determine the load at which the concrete members may crack (Figures 8 and 9). The results indicate that the presence of fibers in admixture significantly improves the concrete splitting tensile strength. Among different admixtures considered, the highest strength value is achieved by the admixture containing S10H10. The splitting tensile strength of S05H15, S10H10 and S15H05 admixtures increase by 77\%, 80\% and 77\% compared to Ref., respectively. In case of hybrid consumption of steel fibers, the summation of each percent of hooked or straight is $2 \%$, therefore, a great deviation between tensile strength of admixtures cannot be seen. Maximum value of tensile strength belongs to $\mathrm{S} 10 \mathrm{H} 10$ admixture with value of $24 \mathrm{Mpa}$. Tensile strength is part of those features that is critical in pre-stressed concrete sleepers, therefore, improving tensile strength of concrete mix design makes sleepers better in dynamic performance.

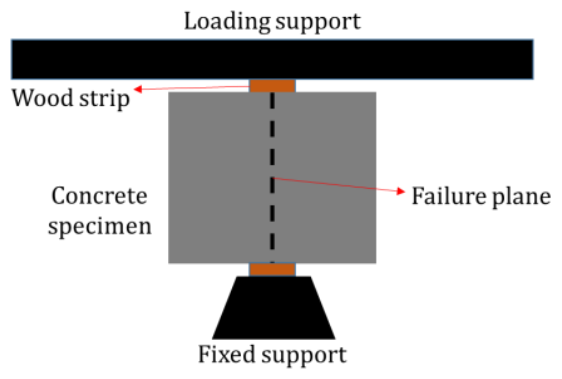

Figure 8

A schematic of Splitting tensile test

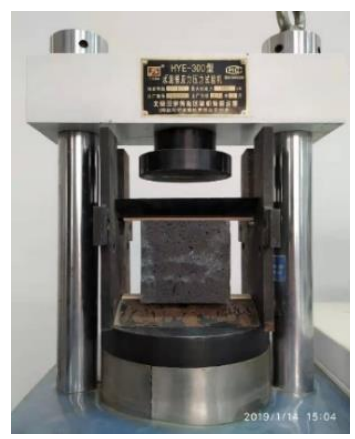

Figure 9

Splitting tensile test layout of concrete specimens 


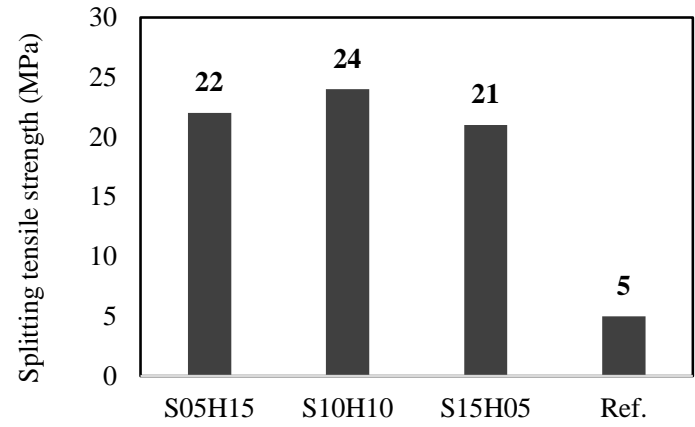

Figure 10

Splitting tensile strength of concrete specimens

\section{Results and Discussion}

This study shows the improvement of the physical and mechanical properties of railway concrete mixtures, by the application hybrid steel fibers. Because, content of more than $2 \%$ steel fiber in concrete mixture, generally, reduces workability and fiber dispersion, it is therefore required to apply a special mix design or special concrete casting techniques. Thus, the concrete mixture has been hybridized by adding fibers with $\mathrm{S} 05 \mathrm{H} 1.5, \mathrm{~S} 10 \mathrm{H} 10$ and $\mathrm{S} 15 \mathrm{H} 05$. The mechanical properties for all mixtures were measured and compared with compressive, tensile and flexural strengths, to determine the performance of railway concrete mix design (Table 3 ).

Table 3

Steel fibers properties

\begin{tabular}{|l|l|l|l|}
\hline \multirow{2}{*}{ Notation } & Compressive strength & Splitting tensile strength & Flexural strength \\
\cline { 2 - 4 } & \multicolumn{2}{|c|}{$\mathrm{MPa}$} \\
\hline Ref. & 93 & 5 & 10 \\
\hline S05H15 & 156 & 22 & 21 \\
\hline S10H10 & 171 & 24 & 22 \\
\hline S15H05 & 169 & 21 & 20 \\
\hline
\end{tabular}

The test results show that the mechanical performance of admixture $\mathrm{S} 10 \mathrm{H} 10$, has the best performance among all the admixtures. It can be due to the same load of single and hooked shape fibers, which provide better mechanical performance for concrete. It can be concluded that to obtain compressive strengths of more than 170 $\mathrm{Mpa}$, hybrid fibers can be an effective solution. Concrete quality plays a critical role in load bearing of concrete sleepers, as well as, its pre-stressing system. Therefore, it is expected as the quality of concrete is increased and the pre-stressing systems 
of conventional pre-stressed concrete sleeper and steel fiber pre-stressed concrete sleeper are identical, steel fiber pre-stressed concrete sleeper shows better performance due to the better mechanical performance of its steel fiber concrete.

\section{Conclusions}

In this study, 4 admixtures are prepared in order to investigate the performance of hybrid fibers and their influence, on concrete railway sleeper mix design. To study hybrid use of steel fibers and compare their behavior, different fiber contents as, (0.5\% straght- $1.5 \%$ hooked), (1\% straght-1\%hooked) and (1.5\% straight$0.5 \%$ hooked) are considered to research. The main focus of the current study is on the mechanical behavior of concrete railway sleeper mix design, by performing compressive strength, flexural strength and splitting tensile strength experiments. The following points can be concluded from this study:

1) $\mathrm{S} 05 \mathrm{H} 15$ has a compressive value $40 \%$ greater than Ref., these percentages for $\mathrm{S} 10 \mathrm{H} 10$ and $\mathrm{S} 15 \mathrm{H} 05$ are $45 \%$ and $44 \%$ higher, respectively.

2) The flexural strength of S05H15, S10H10 and S15H05 increased by 52\%, $55 \%$ and $50 \%$, respectively, compared to Ref.

3) The splitting tensile strength of S05H15, S10H10 and S15H05 admixtures increase by $77 \%, 80 \%$ and $77 \%$ compared to Ref., respectively.

4) S10H10 hybrid steel fiber mix design shows the best performance in case of mechanical properties and is a good choice to fiberize concrete railway sleeper mix design.

\section{Acknowledgement}

This paper has been supported by China Academy of Railway Science foundation (Grant No. 2020YJ081).

\section{References}

[1] A. S. Hameed and A. P. Shashikala, "Suitability of rubber concrete for railway sleepers," Perspectives in Science, Vol. 8, No. Supplement C, pp. $32-35,2016 / 09 / 01 / 2016$

[2] Fischer S. "Investigation of effect of water content on railway granular supplementary layers". Naukovyi Visnyk Natsionalnoho Hirnychoho Universytetu. (3): pp. 064-068, 2021

[3] Gerber, Ulf, Mykola Sysyn, Jandab Zarour, and Olga Nabochenko. "Stiffness and strength of structural layers from cohesionless material." Archives of Transport" 49(1): pp. 59-68, 2019

[4] B. Li, H. Li, M. Siahkouhi, and G. Jing, "Study on coupling of glass powder and steel fiber as silica fume replacement in ultra-high performance concrete: Concrete sleeper admixture case study," KSCE Journal of Civil Engineering, pp. $1-12,2020$ 
[5] P. Qiao, J. F. Davalos, and M. G. Zipfel, "Modeling and optimal design of composite-reinforced wood railroad crosstie," Composite structures, Vol. 41, No. 1, pp. 87-96, 1998

[6] W. Ferdous, A. Manalo, G. Van Erp, T. Aravinthan, S. Kaewunruen, and A. Remennikov, "Composite railway sleepers-Recent developments, challenges and future prospects," Composite Structures, Vol. 134, pp. 158168,2015

[7] J.-A. Zakeri and R. Talebi, "Experimental investigation into the effect of steel sleeper vertical stiffeners on railway track lateral resistance," Proceedings of the Institution of Mechanical Engineers, Part F: Journal of Rail and Rapid Transit, Vol. 231, No. 1, pp. 104-110, 2017

[8] G. Jing, D. Yunchang, R. You, and M. Siahkouhi, "Comparison study of crack propagation in rubberized and conventional prestressed concrete sleepers using digital image correlation," Proceedings of the Institution of Mechanical Engineers, Part F: Journal of Rail and Rapid Transit, p. 09544097211020595, 2021

[9] G. Jing, M. Siahkouhi, J. R. Edwards, M. S. Dersch, and N. Hoult, "Smart railway sleepers-a review of recent developments, challenges, and future prospects," Construction and Building Materials, p. 121533, 2020

[10] Németh A, Fischer S. investigation of the glued insulated rail joints applied to cwr tracks. Facta Universitatis, Series: Mechanical Engineering. 2021 May 14

[11] Kurhan, M., D. Kurhan, R. Novik, S. Baydak, and N. Hmelevska. "Improvement of the railway track efficiency by minimizing the rail wear in curves." In IOP Conference Series: Materials Science and Engineering, Vol. 985, No. 1, p. 012001. IOP Publishing, 2020

[12] Przybylowicz, Michal, Mykola Sysyn, Vitalii Kovalchuk, Olga Nabochenko, and Bogdan Parneta. "Experimental and theoretical evaluation of side tamping method for ballasted railway track maintenance." Transport Problems 15 (2020)

[13] R. Kohoutek, "Dynamic and static performance of interspersed railway track," in Conference on Railway Engineering 1991: Demand Management of Assets; Preprints of Papers, 1991, p. 153: Institution of Engineers, Australia

[14] I. Oladele, A. Akinwekomi, S. Aribo, and A. Aladenika, "Development of fibre reinforced cementitious composite for ceiling application," Journal of Minerals and Materials Characterization and Engineering, Vol. 8, No. 08, p. 583, 2009

[15] W. Abbass, M. I. Khan, and S. Mourad, "Evaluation of mechanical properties of steel fiber reinforced concrete with different strengths of concrete," 
Construction and Building Materials, Vol. 168, pp. 556-569, 2018/04/20/ 2018

[16] M. Ghahremannejad, M. Mahdavi, A. E. Saleh, S. Abhaee, and A. Abolmaali, "Experimental investigation and identification of single and multiple cracks in synthetic fiber concrete beams," Case Studies in Construction Materials, Vol. 9, p. e00182, 2018/12/01/2018

[17] J. Katzer and J. Domski, "Quality and mechanical properties of engineered steel fibres used as reinforcement for concrete," Construction and Building Materials, Vol. 34, pp. 243-248, 2012/09/01/2012

[18] L. Vandewalle, "Postcracking behaviour of hybrid steel fiber reinforced concrete," in Fracture Mechanics of Concrete and Concrete StructuresFraMCoS, in: Proceedings of the $6^{\text {th }}$ International Conference, Catania, Italy, 2007, pp. 17-22

[19] K. A. Sadeghi J, Khabbazi AS, "Improvement of mechanical properties of railway track concrete sleepers using steel fibres," Mater Civ Eng, p. 11, 2016

[20] H. Zhu, S. Cheng, D. Gao, S. M. Neaz, and C. Li, "Flexural behavior of partially fiber-reinforced high-strength concrete beams reinforced with FRP bars," Construction and Building Materials, Vol. 161, pp. 587-597, 2018/02/10/ 2018

[21] H.-O. Shin, J.-M. Yang, Y.-S. Yoon, and D. Mitchell, "Mix design of concrete for prestressed concrete sleepers using blast furnace slag and steel fibers," Cement and Concrete Composites, Vol. 74, No. Supplement C, pp. $39-53,2016 / 11 / 01 / 2016$

[22] A. Parvez and S. J. Foster, "Fatigue of steel-fibre-reinforced concrete prestressed railway sleepers," Engineering Structures, Vol. 141, No. Supplement C, pp. 241-250, 2017/06/15/2017

[23] C. C. Hwang CL, Lee LS, Bui LAT, Hou BS, Hsieh HY., "The material and mechanical property of heavy-duty prestressed concrete sleeper.," Mater pp. 97-98, 2011

[24] AREMA., "Concrete ties.," in Manual for railway engineering American Railway Engineering and Maintenance-of-Way Association, 2006

[25] E. C. f. Standardization, "Railway applications-track-concrete sleepers and bearers part 2: Prestressed monoblock sleepers," 2009 